\begin{abstract}
Iranica
Abstracta Iranica Revue bibliographique pour le domaine irano-aryen

Volume 32-33 | 2013

Comptes rendus des publications de 2009-2010
\end{abstract}

\title{
Adi Erlich. Clay Rhyta from Maresha
}

\section{Astrid Nunn}

\section{(2) OpenEdition}

\section{Journals}

Édition électronique

URL : http://journals.openedition.org/abstractairanica/40250

DOI : 10.4000/abstractairanica.40250

ISSN : 1961-960X

Éditeur :

CNRS (UMR 7528 Mondes iraniens et indiens), Éditions de l'IFRI

Édition imprimée

Date de publication : 1 décembre 2013

ISSN : 0240-8910

\section{Référence électronique}

Astrid Nunn, «Adi Erlich. Clay Rhyta from Maresha », Abstracta Iranica [En ligne], Volume 32-33 | 2013,

document 60, mis en ligne le 01 juillet 2016, consulté le 26 septembre 2020. URL : http://

journals.openedition.org/abstractairanica/40250; DOI : https://doi.org/10.4000/abstractairanica.

40250

Ce document a été généré automatiquement le 26 septembre 2020.

Tous droits réservés 


\title{
Adi Erlich. Clay Rhyta from Maresha
}

\author{
Astrid Nunn
}

\section{RÉFÉRENCE}

Adi Erlich. «Clay Rhyta from Maresha ». Trans. 37, 2009, p. 81-88.

1 Plusieurs dizaines de rhytons en terre cuite ont été découverts dans les habitations et les cavernes sous-jacentes lors des fouilles à Maresha (Marisa, Tel Sandahanna, Israël). Qui s'intéresse aux rhytons en Israël, se réfèrera à cet article qui en présente les différents types : partie animale en forme e.a. d'un cheval - plutôt perse-achéménide ou d'un dromadaire - innovation locale. La seule figuration anthropomorphe et grecque représente Athéna. Contrairement à tous les autres rhytons découverts jusqu'à présent en Israël, ceux de Maresha ne datent pas de l'époque achéménide mais de l'époque hellénistique. Néanmoins, ils présentent un mélange inédit d'éléments achéménides, grecs et locaux qui reflètent une culture symbiotique dans l'est hellénistique.

\section{AUTEURS}

\section{ASTRID NUNN}

Université de Munich 